\title{
Effect of Village Midwife Program on Contraceptive Prevalence and Method Choice in Indonesia
}

\author{
Emily H. Weaver, Elizabeth Frankenberg, Bruce J. Fried, Duncan Thomas, Stephanie B. \\ Wheeler, and John E. Paul \\ Emily H. Weaver is Fogarty Global Health Fellow, School of Medicine, University of North \\ Carolina at Chapel Hill, 130 Mason Farm Road, Campus Box 7030, Chapel Hill, NC 27599. \\ Elizabeth Frankenberg is Professor of Public Policy and Sociology, Sanford School of Public \\ Policy, and Duncan Thomas is Norb F. Schaefer Professor of International Studies, Department \\ of Economics, Duke University. Bruce J. Fried is Associate Professor, Stephanie B. Wheeler is \\ Assistant Professor, and John E. Paul is Clinical Professor, Department of Health Policy and \\ Management, Gillings School of Global Public Health, University of North Carolina at Chapel Hill \\ Emily H. Weaver: emweaver@email.unc.edu
}

\section{Abstract}

Indonesia established its Village Midwife Program in 1989 to combat high rates of maternal mortality. The program's goals were to address gaps in access to reproductive health care for rural women, increase access to and use of family planning services, and broaden the mix of available contraceptive methods. In this study, we use longitudinal data from the Indonesia Family Life Survey to examine the program's effect on contraceptive practice. We find that the program did not affect overall contraceptive prevalence but did affect method choice. Over time, for women using contraceptives, midwives were associated with increased odds of injectable contraceptive use and decreased odds of oral contraceptive and implant use. Although the Indonesian government had hoped that the Village Midwife Program would channel women into using longer-lasting methods, the women's "switching behavior" indicates that the program succeeded in providing additional outlets for and promoting the use of injectable contraceptives.

Quality reproductive health care has the potential to improve outcomes for mothers, children, and families, in part by empowering women to regulate their own fertility and receive enhanced care during pregnancy and delivery. The 1994 International Conference on Population and Development (ICPD) fueled efforts to improve access to reproductive health care by creating international consensus that reproductive health is a right and defining it broadly as "a state of complete physical, mental, and social well-being, and not merely the absence of disease or infirmity, in all matters relating to the reproductive system and to its functions and processes." Further, the ICPD Programme of Action stated that men and women have the right to safe, effective, affordable, and acceptable contraceptive methods. After the conference, provision of reproductive health care emerged as a key intervention to reduce the burden of maternal mortality, promote women's health and reproductive autonomy, improve birth outcomes, and increase family welfare in developing countries. In 2005, universal access to reproductive health care was added to the United Nations Millennium Development Goals. In 2012, with sponsorship from the Bill \& Melinda Gates Foundation, the United Nations Population Fund (UNFPA), the UK government, and others, the London Summit on Family Planning launched a global movement to promote and achieve universal access to contraceptives by 2020 (Carr et al. 2012) 
Studies suggest that access to contraceptives can potentially reduce maternal and child mortality by allowing adequate birth spacing and thereby decreasing the risk of low-birthweight babies, preventing unwanted and high-risk pregnancies, and decreasing the frequency of unsafe abortions (WHO 1995; Glasier et al. 2006; Ahmed et al. 2012; Cleland et al. 2012). The ability to manage fertility and the timing of births likely improves family circumstances by reducing stress on family resources including time, income, and wealth (UNFPA n.d.). Some studies demonstrate that safe and effective fertility regulation leads to increased economic development (Schultz and Zeng 1995; Maralani 2008; Schultz 2009; Canning and Schultz 2012). Contraceptive choice is another essential component of reproductive and sexual rights, as defined by ICPD. Access to a variety of contraceptive methods is known to improve reproductive health outcomes, including increased uptake of contraceptives, improved health, and lower rates of discontinuation (Gray et al. 2006). The type of method chosen also affects contraceptive security for women, with those relying on short-term resupply methods being more vulnerable to disruption in the supply chain than are women using implants, IUDs, or sterilization (Ross 2003).

Contraceptive use and choice of method are affected by individual and community factors, access to reproductive health care services, and provider characteristics (Lerman et al. 1989; World Bank 1991; Jensen 1996; DeGraff, Bilsborrow, and Guilkey 1997; Koenig, Hossain, and Whittaker 1997; Oddens and Lehert 1997; Konje et al. 1998; Steele, Curtis, and Choe 1999; RamaRao et al. 2003; Stephenson, Beke, and Tshibangu 2008). Evidence is mixed regarding the factors most closely associated with method choice. Some studies have found that provision of information concerning contraceptive methods is most critical to determining method choice, whereas others conclude that providers' recommendations are most important (Oddens and Lehert 1997; Ekani-Bessala et al. 1998; Konje et al. 1998). Other government or programmatic contextual factors may also influence contraceptive practice, for example, media messages or government-sponsored educational campaigns (Oddens and Lehert 1997; Magadi and Curtis 2003; Schoemaker 2005).

Community-based distribution of contraceptives is a popular method of extending access to family planning services. This type of distribution relies on nonclinical, community-based family planning workers (or volunteers), and often targets rural communities that have limited access to formal health care services. Community-based distribution has been found to be effective in increasing access to and use of contraceptives in Indonesia and a number of other settings (Warwick 1986; Gertler and Molyneaux 1994; Kambo et al. 1994; Sultan, Cleland, and Ali 2002; Utomo, Arsyad, and Hasmi 2006; Hoke et al. 2011; Krueger et al. 2011; McKelvey et al. 2012). In 1984, after a decade of contraceptive distribution through village contraceptive distribution centers, Indonesia's National Family Planning BoardBKKBN —implemented a community-based distribution approach that employed a large network of family planning fieldworkers and a designated volunteer in each community. The family planning fieldworkers distributed pills and condoms, visited contraceptive acceptors, recruited new acceptors, persuaded community leaders to support the BKKBN program, and coordinated program activities through regular community visits. The volunteers helped coordinate community outreach activities and distribute pills and condoms on a continuous basis under the supervision of the fieldworkers (Warwick 1986). After many years of successful community-based distribution in Indonesia, the Village Midwife Program was introduced in 1989, primarily to address issues of maternal mortality but also to serve as an additional source of contraceptive supply. This program hinges on the midwives' widespread availability and their intimate relationships with clients before, during, and after childbirth. BKKBN's community-based distribution program began to change in 2000 as decentralization occurred and has been scaled back dramatically during the past decade. 
The launch of the Village Midwife Program positioned Indonesia as an early adopter of widespread reproductive health care service provision. A key goal of this program was to train and place village midwives throughout the country. In this study, we investigate the relationship between the Village Midwife Program and women's choice and use of contraceptives. Our study focuses on Indonesia during the 14-year period from 1993 to 2007 , a period during which massive expansion of midwifery services took place across the country. Using a fixed effects logit specification, which identifies the program's effect under certain assumptions, we assess the extent to which the expansion in access to midwifery services was accompanied by changes in women's contraceptive practice. Although provision of contraceptive services was one of the core responsibilities of village midwives, no previous studies have evaluated the impact of a community's access to a midwife on community contraceptive practices.

\section{INDONESIA'S VILLAGE MIDWIFE PROGRAM}

The Village Midwife Program was introduced to reduce maternal mortality by addressing gaps in access to reproductive health care for rural women. The program's primary goals were to expand safe motherhood among poor and hard-to-reach populations, improve accessibility and use of family planning services, and enhance the mix of contraceptive products available to target populations. Village midwives were contracted by the Indonesian Ministry of Health (DepKes) to complement DepKes's community health clinic infrastructure and BKKBN's family planning program, which provided access to the pill and condoms throughout the country through the existing community-based distribution network (World Bank 1991). The village midwives expanded the method mix available in many rural locations by providing more convenient access to injectables and, to a limited extent, clinical contraceptive methods such as contraceptive implants and IUDs.

The Village Midwife Program expanded rapidly and its workforce increased from approximately 5,000 in 1987 to 80,000 in 2009 (World Bank 2010). The community survey component of the Indonesia Family Life Survey (IFLS) provides longitudinal data collected across 312 communities over a 14-year period from 1993 through 2007. The survey documents the major expansion in village midwife services that occurred in the two decades after the program's inception. From 1993 to 1997, the percentage of IFLS communities that had a village midwife increased from 9.6 to 46.3 percent. By 2007, this percentage rose to 58.8 percent. Most village midwives were initially recruited from nursing programs and received one additional year of midwifery training. The training requirement was later amended to require that village midwives attend a three-year midwifery academy. The village midwives were guaranteed a government salary for at least three years, during which time they were also expected to establish a private practice that would sustain them after their public service tenure expired. That midwives were encouraged to develop a practice that would eventually be self-sustaining raises the question of whether they faced a conflict at times between maximizing their revenue and following government policy guidelines.

Upon entry into the program, the village midwives were largely in their early twenties and single. They were predominantly placed in their province of origin, and placement was generally more difficult in smaller, more remote areas. In the early stages of the program, the midwives' practices were typically stationed at the village delivery post or, in the absence of such a post, at the home of the village leader. The young midwives often experienced difficulty starting up their practices. Barriers cited included community members' perception that village midwives were too young and inexperienced to provide midwifery services, women's long-standing reliance on traditional midwives (who frequently viewed the village midwives as a threat to their livelihoods), and lack of adequate equipment and supplies. Additional challenges included gaining the community's 
acceptance and threats to personal security (Hull, Rusman, and Hayes 1998; Frankenberg and Thomas 2000; Strauss et al. 2004 and 2009; focus group discussion with village midwives, May 2011). The midwives offer many services associated with women's reproductive health, together with immunizations, well-child care, and a variety of acutecare services such as sick-patient visits, the administering of antibiotics, and attending to wounds (Frankenberg and Thomas 2001; Frankenberg, Sikoki, and Suriastini 2003).

At the time the Village Midwife Program was established, BKKBN's Family Planning Program advised women younger than 30 years of age to have only two children and to delay their first birth until after age 20. Women older than 30 and those with three or more children were advised not to have any more children. In addition to providing an additional access point for contraceptive distribution, village midwives were to promote longer-lasting and/or clinical methods of contraception (IUDs and implants) for women who had already achieved their preferred family size. Program planners also aimed to increase access to contraceptives: (1) for specific groups who underused family planning services (for example, lower-income families, women having little education, and women living in rural communities or informal urban communities), and (2) in areas having limited access to family planning services (for example, remote, poor coastal, and transmigrational communities) (World Bank 1991).

The Village Midwife Program has been successful in yielding improvements in a variety of health outcomes, including increases in women's receipt of iron tablets, use of antenatal care among certain subgroups, choice of a medically oriented delivery, and body mass index for women of reproductive age and the birth weights of their children, and a decreased incidence of stunted growth among children (Frankenberg and Thomas 2001; Frankenberg, Suriastini, and Thomas 2005; Frankenberg et al. 2009). Although no studies to date have evaluated the Village Midwife Program's effect on contraceptive use, the contraceptive prevalence rate (percent using a modern method) has risen since shortly after the program's inception from 47 percent in 1991 to 57 percent in 2007, and the total fertility rate dropped from 3.0 in 1991 to 2.6 in 2007 (Statistics Indonesia and Macro International 2008). ${ }^{1}$ Preliminary results from the 2012 Indonesia Demographic and Health Survey (DHS) show, however, that contraceptive prevalence has risen only 2 percentage points for all methods and 1 percentage point for modern methods during the past decade. These preliminary results measure the TFR to be 2.6 and unmet need for contraception among currently married women as 11 percent (Statistics Indonesia et al. 2012).

Village midwives could theoretically influence uptake or use of contraceptive methods through both supply- and demand-side channels. They could increase supply through increased access to a convenient distribution channel or through the availability of different or more individually appropriate methods. They could influence demand through provision of information and counseling or through influencing women's fertility goals. The impact of village midwives may also have varied over time as the midwives became more experienced or more familiar with and accepted by community members. To draw lessons from Indonesia's long-term investment in reproductive health in light of current challenges, we examine the Village Midwife Program's effect on contraceptive use and method choice for all ever-married reproductive-aged women and selected target populations.

\footnotetext{
${ }^{1}$ Drawing upon data from the Indonesia Demographic and Health Survey, Hull and Hartanto (2009) adjust for missing single women and report an adjusted fertility rate of 2.3 in 2007.
} 


\section{METHODS}

We use data from all four full rounds of the IFLS, which is a longitudinal demographic, socioeconomic, and health survey of Indonesian individuals, their households, families, and the communities in which they live. The sampling frame covers 13 provinces and was designed to be representative of 83 percent of the Indonesian population at the time of the 1993 baseline (Frankenberg and Karoly 1995a). Follow-ups have been conducted in 1997, 2000, and 2007, creating one of the longest-running, multilevel, large-scale longitudinal surveys in the developing world. Our study draws on two sources of data from the survey: (1) interviews with ever-married women of reproductive age (women who are currently married, divorced, or widowed, and are between the ages of 15 and 49), and (2) interviews with the village leader or head of the local women's organization (referred to as "community informants"). Our analyses include all ever-married women who lived in the sampled communities in any of the survey waves. They include the baseline age-eligible female panel respondents, respondents who age into the sample, and women who join the households of panel members in the communities, typically through marriage to a male panel respondent. Women may become ineligible over time if they reach their fiftieth birthday, become infecund, or are pregnant at the time of their interview. Furthermore, the study is limited to women residing in IFLS's 312 baseline communities. ${ }^{2}$ Women who have moved from one IFLS community to another are included in the analyses regardless of whether they have been found in another IFLS community or in their original baseline community. Women who are not living in a baseline community are not included in the analysis. Thus, the few women who moved from an IFLS community to a non-IFLS community are not surveyed.

The overall reinterview rate of women in the age group we selected was more than 97 percent in the 2000 and 2007 survey waves (Strauss et al. 2009). When controlling for select individual and community characteristics, communities' receipt of a village midwife is not significantly associated with women's migration out of study communities or loss to followup over the study period. Because attrition is not correlated with our intervention (specifically, whether a community has a midwife), we conclude that attrition is not likely to be a source of bias in our results.

We first examine contraceptive use for ever-married reproductive-aged women (15-49 years) present in 1993, 1997, 2000, and 2007 who are "eligible" for contraceptive use (that is nonpregnant women who are able to conceive), resulting in a total sample of 8,531 women (16,181 woman-year observations). Second, we examine contraceptive choice for each current contraceptive user during the same time period ( $\mathrm{n}=5,015$ women; 9,874 woman-year observations).

\section{Statistical Approach}

Evaluation of health and reproductive health programs is complicated, given the multiple levels of influence (individual, household, community) on contraceptive use and method type, and the general lack of comprehensive, high-quality data. A key challenge confronting many evaluations is that programs are seldom randomly placed. Governments employ various targeting strategies to achieve different goals. They may target the most accessible populations to achieve the largest effect, or populations with low access to health services or relatively high levels of need. Whereas targeting is frequently essential to achieve program goals, it creates a complex statistical challenge for program evaluation. Specifically, when

\footnotetext{
${ }^{2}$ IFLS defines a community as a desa (village) in a rural area, or a kelurahan (neighborhood or township) in an urban area. In rural areas, the average community size is just over 3,300 individuals and encompasses 4.8 square kilometers. In urban areas, communities have three times as many individuals living in one-third the area (Frankenberg and Karoly 1995b).
} 
programs are not randomly placed, any unobserved correlation between community- or individual-level determinants of health that relate to program placement and health outcomes may bias estimates of program impact. If purposive program placement were based only on observed characteristics, this correlation would pose no significant challenge to linking program impact with health outcomes. If placement is based on unobserved characteristics or causes any form of migration into program communities, however, estimates may be biased in the absence of methodological means to control for this endogeneity (Rosenzweig and Wolpin 1986; Angeles, Guilkey, and Mroz 1998).

One approach to identifying the influence that midwives have on choices made by women in a community is to compare the behavior of the women before and after the midwife has been introduced with the behavior of the women in communities that did not receive the services of a midwife. To the extent that everything in the community that affects contraceptive behavior is fixed during this time, other than the introduction of the midwife, then observed changes can be attributed to the introduction of the midwife. In that instance, the community fixed effects estimates will absorb unobserved, fixed differences between communities and exploit the variation in the timing of the introduction of the midwife across communities to identify the causal effect of the midwife. This approach has been successfully used to evaluate the shorter-term effects of the Village Midwife Program and the effects of other public programs in Indonesia (Rosenzweig and Wolpin 1986; Gertler and Molyneaux 1994; Frankenberg and Thomas 2001; Frankenberg, Suriastini, and Thomas 2005; Franken-berg et al. 2009).

Following this strategy, we include a community fixed effect in the empirical models to control for the government of Indonesia's placement strategy to assign village midwives to disadvantaged communities. Community-level regressions that related the presence of a village midwife to measures of village infrastructure and socioeconomic development indicate that midwives were more likely to be placed in rural villages with low levels of infrastructure. These results are consistent with earlier work evaluating placement of the Village Midwife Program (Frankenberg and Thomas 2001; Frankenberg, Suriastini, and Thomas 2005; Frankenberg et al. 2009), and confirm that the village midwives were consistently placed in rural villages with low levels of infrastructure. We find no evidence that the placement of village midwives is significantly associated with observed fertility characteristics, indicating that midwife placement was not associated with levels of attained or desired fertility. Nonetheless, the results regarding infrastructure emphasize the importance of including community fixed effects to take into account unobserved timeinvariant community-level characteristics associated with women's contraceptive practice and a community's receipt of a village midwife. ${ }^{3}$

Our evaluation of the Village Midwife Program spans a 14-year period during which Indonesia underwent substantial changes, including the Asian economic crisis, the subsequent transition to democracy, and increased decentralization of public services. As a result, allowing for time-varying community-level changes in the empirical models is also important to better isolate the impact of village midwives on contraceptive choices in the communities. To this end, the models are extended to include time effects, one for each survey wave, and interactions between the time effects and the presence of a village midwife. These more flexible models allow the effect of the midwife program to vary over time. Thus, our model is specified as follows:

\footnotetext{
${ }^{3}$ Estimates of the effect of the midwife will be biased if unobserved individual-specific characteristics exist that affect both contraceptive choices and migration into or out of communities having a midwife. We have explored the extent to which this type of selective migration contaminates the estimates by re-estimating the models placing respondents in their communities at the baseline survey. Whereas overall these estimates are slightly less precise (because of more measurement error in exposure to the village midwife), the magnitudes of the estimated effects are similar to those reported below and our main conclusions are not affected.
} 


$$
Y_{i c t}=\beta_{0}+\beta_{1} M_{c t}+\beta_{2} M_{c t} * T I M E+\beta_{3} T I M E+\beta_{4} X_{i t}+\beta_{5} X_{c t}+\left(v_{c}+\varepsilon_{i c t}\right),
$$

where $Y_{i c t}$ is the outcome (either contraceptive use or contraceptive method type) for woman $i$ in community $c$ in time $t ; M_{c t}$ is an indicator of village midwife availability in community $c$ at time $t ; X_{i t}$ is a set of individual-level characteristics at time $t$ such as age, education level, and so forth; $X_{c t}$ is a set of community-level characteristics in time $t$ such as health services, infra-structure, and socioeconomic development indicators; and TIME indicates the year of survey. The error term is made up of two components: $v_{c}$, which is the community fixed effect, and $\varepsilon_{i c t}$, which are unobserved time-variant factors of individual $i$ in the community $c$ at time $t$.

More flexible models would also interact the individual- and community-level characteristics, $X$, with the time fixed effects. Those models suffer from lack of power to separately distinguish the effects of the introduction of village midwives from the effects of other innovations in the communities. Given that we focus on contraceptive choices that are less likely to be as directly affected by the introduction of roads, sewage systems, and possibly other health services as they are by the introduction of midwives, we report estimates of the model specified, excluding these additional interaction terms. Recognizing that our estimates of the time-varying effects of midwives on contraceptive choices may also reflect the impact of other contemporaneous changes that occurred in the study communities is important, however.

We consider two separate outcome measures of contraceptive practice $\left(Y_{i c t}\right)$ in our study. First, we examine whether women use any modern contraceptive by creating a binary indicator of use. A positive value for this variable indicates that the women reported using a modern contraceptive method at the time of the survey, including pills, injectable contraceptives (offering protection for 1, 2, or 3 months), a contraceptive implant, an IUD, a diaphragm, condoms (male and female), or female or male sterilization. Second, we examine contraceptive method choice by creating binary variables for commonly used method types (for example, pills, injectables, implants, and IUDs). All women in this subsample of women aged 15-49 who are not pregnant, who are able to conceive, and who report practicing a modern method of contraception are included in this analysis.

We estimate fixed effects logit regressions for contraceptive use and method choice and also test for differential effects by the government's targeted subgroups of women: women who are uneducated, have low income, live in rural areas, are 30 years of age or older, have three or more children, and have achieved their ideal family size. ${ }^{4}$ Fixed effects logit estimates are only defined if outcomes (and a linear combination of all covariates) vary over time at the level of the fixed effect. In our case, if a community is comprised of women whose outcomes do not vary at all over the study period-that is, communities in which no woman switches between methods during the 14-year study period-these communities do not contribute information to our estimates. For our first outcome — contraceptive use-16,533 women in 311 out of the 312 communities contribute information. The number of women and communities contributing to estimates for contraceptive method choice varies by method type, ranging from 9,829 women in 305 communities for injectables to 6,140 women in 164 communities for implants.

\footnotetext{
${ }^{4}$ Our choice of estimation method weighed the benefits of a logit model relative to a multinomial logit or probit model. We selected the logit model because (1) estimating and interpreting logit models that include fixed effects are straightforward, and (2) the logit model facilitates direct comparisons of specific method types against all other method choices, in contrast with estimates that are relative to an excluded category in multinomial models.
} 
Although this strategy has been used successfully in earlier studies of the Village Midwife Program, it has several limitations. First, the strategy does not account for time-variant unobserved community-level characteristics that may be related to midwife placement, or time-variant individual-level characteristics that are not observed. Second, we cannot estimate the effects of time-invariant community characteristics that may influence our outcomes, because these factors are eliminated from the model by the inclusion of the community fixed effect. Finally, the study's "intent to treat" approach means that village midwives are assigned at the community level (and not to individuals). Thus, the analyses do not measure women's direct exposure to the village midwives via use of their services (only the exposure that occurs from residing in the same village). All analyses were performed using STATA software.

\section{RESULTS}

On average, the women in our sample were 32 years old, had 7 years of education, and had 2.5 children. Figure 1 shows the percentage of women using a modern contraceptive method and the type of method used by women in our sample during each survey wave. Use of contraceptives remained fairly constant between 1993 and 2007, whereas the method mix changed substantially. The most common type of contraceptive method in 1993 was the pill, followed by injectables. IUDs made up approximately one-fifth of all modern contraceptives used at that time. During the next 14 years, the use of pills and IUDs decreased, whereas the percentage of women using injectable contraceptives increased.

\section{Contraceptive Prevalence}

As a preliminary step, we estimated our model excluding the interaction term between the Village Midwife Program and survey year (that is, time), which provides an estimate of the overall association between the presence of a village midwife and contraceptive use during the 14-year study period. The estimate of the "main effect" is not statistically significant, indicating that when averaged across all years, the program is not associated with contraceptive use (results not shown). Given the important contextual changes that occurred in Indonesia during the study period (explained above), however, we present results of the model that allows the program effect to vary over time. Specifically, Table 1 shows the results of a logistic regression model with community fixed effects that includes interaction terms to test for a differential effect of the village midwives on contraceptive use over time. The odds ratios of greatest interest are the interaction terms between the presence of a village midwife and time (survey year). We find that the interaction effect is small in all years and below standard levels of significance, indicating that the village midwives did not affect contraceptive prevalence in any survey year. Other community characteristics are found to be not associated with contraceptive use.

Our results reveal that women's age and education level are highly significant predictors of contraceptive use. Women in older age groups and who have more education have significantly higher odds of using contraceptives than do women in the reference categories (women aged 15-19 and women having no education).

Because the Indonesian government's strategy included the goal of reaching specific demographic groups to increase use of contraceptives, we also tested whether the Village Midwife Program had a differential effect on contraceptive use among those target groups. Women targeted by the BKKBN family planning program were either viewed as least likely to accept family planning (women who live in rural communities, are uneducated, and live in low-income families), or viewed as appropriate populations for use of long-lasting methods (women older than 30 years of age, with three or more children, or who had 
achieved their ideal family size). Contraceptive use among these targeted subgroups was not associated with the presence or absence of a village midwife (results not shown).

\section{Contraceptive Choice}

To estimate the village midwives' effect on women's contraceptive choice, we conducted a series of multivariate logistic regressions predicting the odds of choosing a particular method among women who practiced contraception, comparing women's choice in communities with and without a village midwife. The "main effects" of these method choice models (specifically, models without an interaction term with time) indicate the influence of the village midwives on women's choice of a particular method over the entire study period. These models reveal that, overall, the Village Midwife Program was positively associated with the choice of injectable contraceptives and negatively associated with the choice of the pill among women in program communities, compared with women in communities not having a midwife (results not shown).

Given the vast changes in the country that took place during the study period, however, these "main effects" models may mask important temporal variation in the program's effect. Therefore, we present the results of our model examining the midwives' time-varying influence (Table 2). As with contraceptive use, women's age and educational levels were strongly associated with method choice. Compared with women aged 15-19 (our reference group), women in higher age groups had lower odds of injectable use and greater odds of IUD use. Compared with uneducated women, women who had more education also generally had lower odds of pill and implant use; women who had the highest education levels (10-12 and 13-19 years) had greater odds of IUD use. With regard to injectable contraceptives, only women educated at the primary level (1-5 years) had significantly greater odds of injectable contraceptive use compared with uneducated women.

We controlled for, and do not report, the same community characteristics included in our analysis of contraceptive use (for example, health services and physical infrastructure). The number of hospitals was the only community-level characteristic that significantly affected method choice; this indicator was associated with higher odds of women's use of IUDs and lower odds of injectable and implant use.

Because the effect of midwife availability on contraceptive choice depends on the time period in which it is estimated (specifically, the interaction term positions the time variable as an effect modifier), the odds ratios associated with midwife availability and time in Table 2 may not be directly interpreted. Therefore, Table 3 provides odds ratios for the interaction between village midwife availability and time on contraceptive method choice, taking into account the joint variance of the interaction terms. These estimates indicate the odds of women's choice of a contraceptive method in communities with and without a village midwife by survey year, compared with women in communities without a midwife in 1993 (the reference category). Access to a village midwife may have been less influential in the program's early years, when village midwives were relatively unknown to the community. Women may have been less inclined to seek a village midwife's services or trust her to provide contraceptive counseling and supplies. As the program matured, women may have become more comfortable with village midwives, and the midwives may also have become more skilled in obtaining clients.

We found that village midwives considerably impacted the use of hormonal resupply methods in later years of the program. Village midwives were highly associated with use of injectable contraceptives in their communities in 2007. Women in communities having a village midwife in 2007 had 1.67 times greater odds of using injectable contraceptives than did women in communities without a midwife in 1993. At the same time, women in 
communities that had a village midwife had lower odds of pill use in $2000(\mathrm{OR}=0.70)$ and 2007 (OR = 0.71) and of implant use in $2007(\mathrm{OR}=0.42)$ than did women in communities not having a village midwife in 1993 . The prevalence of IUDs was not affected by the presence or absence of a village midwife in any year.

\section{Contraceptive Choice among Targeted Groups}

One goal of the Family Planning Program was to reach specific demographic groups to promote longer-lasting methods (World Bank 1991). Thus, we tested whether village midwives had a differential effect on contraceptive choice among these target groups. Based on the Indonesian government's strategy, one would expect that women living in communities having a village midwife who are older than age 30, have achieved their ideal family size, or have three or more children have greater odds of using long-lasting methods (IUDs and implants) than do women in communities not having a village midwife. Our subgroup analyses reveal that, similar to the reproductive-aged population as a whole, women in targeted groups in communities having a village midwife had higher odds of injectable use and lower odds of pill use, compared with nontargeted women in communities without a village midwife (Figures 2-4). Furthermore, the presence of village midwives had no effect on IUD or implant use among targeted Indonesian women studied. In contrast, in communities not having a midwife, women in targeted groups had lower odds of injectable use and higher odds of IUD use than did other women.

\section{DISCUSSION}

Frankenberg and colleagues (2009) revealed that the Village Midwife Program had a positive effect on the use of reproductive health services, including use of a skilled birth attendant, taking iron supplements, and receiving antenatal care. This study used a multilevel framework to examine the effect of the Village Midwife Program on contraceptive prevalence and method choice in Indonesia over a 14-year period. We found that the Village Midwife Program did not influence contraceptive use but that village midwives influenced contraceptive methods used by women. In communities having a village midwife, women had significantly greater odds of using injectable contraceptives and significantly lower odds of using pills. Although placement of village midwives in rural communities has aimed to enhance the supply and method mix of contraceptives available to all women, the Indonesian government targets specific subgroups of women for use of longlasting methods (IUDs and implants). The village midwives influenced targeted subgroups of women to switch from oral to injectable contraceptives as opposed to switching to IUDs or implants. These outcomes are consistent with known incentive structures; provision of injectable contraceptives is a source of supplemental income for village midwives, the majority of whom staff a private practice in addition to their public duties (Hull and Mosley 2009).

Increased use of injectables may be attributed to women's preferences irrespective of midwives' financial incentives, however. A trend toward injectable contraceptive use is not unique to Indonesia and is especially prevalent in sub-Saharan Africa (Seiber, Bertrand, and Sullivan 2007). In Kenya, Magadi and Curtis (2003) observed notably higher levels of injectable use among rural, uneducated women and women with less exposure to family planning media messages. In Madagascar, a pilot study of community-based distribution of contraceptives revealed an increase in prevalence of contraceptives, and specifically of injectables (Hoke et al. 2011). A 2007 DHS Comparative Report (Khan et al. 2007) provides data regarding method mix for several other Southeast and South Asian countries. The report shows that injectable contraceptives are considerably more prevalent among modern contraceptive users in Indonesia (49 percent) than in other countries in the region (ranging from 1 percent in Vietnam to 39 percent in Cambodia). 
Although longer lasting than pills, injectable contraceptives are considered hormonal resupply methods and are associated with higher rates of discontinuation and odds of unwanted births in Indonesia than the rates and odds associated with IUDs and implants (Steele and Curtis 2003; Statistics Indonesia and Macro International 2008; Withers, Tavrow, and Abe 2012) and leave women vulnerable to disruptions in the supply chain (Ross 2003). Contraceptive discontinuation, which rose between 2002 and 2007, is of increasing concern in Indonesia and elsewhere. According to the 2007 Indonesia DHS, the most common reasons for discontinuation among married women were health concerns, side effects, and the desire to become pregnant. Although less frequently targeted by family planning programs, the portion of women who discontinue use (and do not wish to become pregnant) may be served by village midwives through education and counseling regarding health concerns and side effects.

As previously noted, the relatively infrequent use of implants and IUDs in Indonesia indicates that the midwives have not been effective advocates for these methods of contraception. In fact, targeted women in communities not having a village midwife had higher odds of IUD use than any other group of women. Meeting the need of women who desire these long-acting methods could result in a substantial reduction in unplanned pregnancies, maternal and infant mortality, and morbidity (Wickstrom and Jacobstein 2011). Promoting the use of IUDs and implants may be difficult for several reasons. One study found that women may prefer contraceptive methods that do not require a pelvic exam, especially in conservative communities (Warwick 1986). Research conducted in the 1990s also indicated that some women had problems getting providers at public health clinics to remove implants and IUDs upon request, especially prior to their expiration (Hull 1998). These women were at times directed to private clinics where they may have faced higher fees for removal of the implant/IUD. Such barriers could potentially be addressed through interventions to improve compliance with removal and expiration dates, such as standard guidelines for education and counseling regarding timely removal for women, and mandates for public clinics to provide these services upon request. Furthermore, provider incentives for promoting IUDs and implants are not aligned with the government's targets. Indonesian women also lack access to high-quality sterilization services, especially in remote areas, which, given the method's cost-effectiveness and efficacy at preventing unwanted pregnancies (Cleland et al. 2006), is also a disadvantage for Indonesian women who want to stop childbearing.

Although not directly measured in the analyses, issues associated with the supply chain for clinical methods may also present challenges. IFLS data revealed that fewer than half of the village midwives provided IUD services. Importantly, women may not be willing to switch to less popular method types (for example, IUDs and implants) if methods are inconvenient to obtain or the women are not confident that they will be able to obtain follow-up services for clinical methods. IUDs and implants, in particular, place especially high demands on the service-delivery system, requiring skilled and carefully trained providers, a functioning logistics system, attention to counseling and provision of complete information for clients, easy access to providers who can remove the implants/IUDs on demand, and ideally a sophisticated follow-up system to notify clients of the need for removal (Fisher et al. 1997). Sterilization, although highly effective, is seldom used in Indonesia, and also requires significant health care investments and infrastructure. Although significant investments have been made in the Indonesian health system to ensure access for all populations, disparities remain that affect the availability of services required for consistent and high-quality provision (and removal) of clinical methods in nonurban areas.

Our results differ from research in other settings that have shown contraceptive prevalence as being responsive to improvements in service availability (Jain 1989; Gray et al. 2006). 
The limited effect of the Indonesia Village Midwife Program on contraceptive prevalence may be a result of a number of factors. The long history of family planning fieldworker services in Indonesian communities may already have reached the population of women most easily influenced by increases in service availability prior to the collection of our survey data. An earlier study by Gertler and Molyneaux (1994) indicated that supply-side constraints (for example, service availability) were not a factor in fertility decline at that time and that future gains in contraceptive prevalence were likely to be most affected by interventions that promoted increases in demand (rather than interventions that expanded the distribution system, such as the Village Midwife Program). This hypothesis is consistent with our findings and points to a need for additional strategies to increase contraceptive prevalence by addressing unmet need through targeted, demand-side interventions.

The implications of this study are that increases in access to family planning services in Indonesia may have reached a saturation level, wherein contraceptive uptake is no longer responsive to additional service inputs. As early as the mid-1980s, the contraceptive distribution system, although limited in method mix, was extensive and highly responsive to increases in demand (Gertler and Molyneaux 1994). Increased access to additional family planning service providers who have the capacity to provide clinical methods (that is, village midwives) has not increased prevalence. Although many early programs that targeted family planning in Indonesia and other settings found contraceptive demand responsive to changes in supply during the 1970s and 1980s, evidence concerning this relationship since that time has been mixed (Frankenberg et al. 2009).

More research is needed to understand the influences on contraceptive uptake in health systems where contraceptive supply no longer constrains women's ability to obtain a contraceptive method. Although some women may not desire to use contraceptives (or the contraceptive method available to them, if the range of methods is limited), Indonesian women classified as having "unmet need" are appropriate targets for policy intervention. Whereas accessing contraceptives may not be a barrier for Indonesian women, other factors may inhibit contraceptive use for women with unmet need. According to the 2007 Indonesia DHS, Indonesian women with unmet need who do not intend to use contraceptives in the future cite method-related concerns (for example, fear of side effects) as a major reason for not practicing contraception. A small proportion of these women indicate that they want as many children as possible (10 percent), the woman or her husband is opposed (17 percent), or the woman lacks knowledge ( 9 percent) (Statistics Indonesia and Macro International 2008). Education and counseling by village midwives have the potential to address unmet need among women with method-related concerns. The village midwives are mainly demand-based providers, however, and a more proactive means for identifying and reaching women with unmet need may be necessary.

\section{CONCLUSION}

This study analyzes a well-known and highly successful program in Indonesia designed to improve access to reproductive health care for women in underserved areas. By exploiting the temporal variation in implementation of the Village Midwife Program and the longitudinal nature of the IFLS, this study examined the effect of the program on contraceptive use and method choice. The main policy implications of these analyses are that although the Village Midwife Program has not increased overall contraceptive prevalence, it has provided women with a reliable contraceptive source for injectable contraceptive methods, and midwives have facilitated women's switching from oral to injectable methods. The evidence suggests, however, that a substantial population of women remains for whom IUDs and implants may be more appropriate and possibly desirable. The predominant use of hormonal contraceptives (the pill, injectables) in Indonesia is of concern 
to policymakers because of their relatively high failure and discontinuation rates and because of the large proportion of women for whom long-lasting methods are thought to be more appropriate (Hull and Mosley 2009; Syarief 2010). Efforts are underway to promote long-lasting method types through the training of doctors and midwives and through community-based events (Syarief 2010; BKKBN 2012a, 2012b, and 2012c). Midwives might be encouraged to discuss postpartum contraceptive use with women whose babies they have delivered, particularly if these mothers want to stop childbearing or want a lengthy delay before a subsequent pregnancy.

The original intention of the Village Midwife Program was to improve localized access to long-lasting clinical methods for women (World Bank 1991). The low prevalence of implants and IUDs indicates that this result did not occur. Updated research is needed to identify demand-side factors affecting lack of uptake of clinical methods (for example, cultural acceptance). Although not directly addressed in this study, demand-side research to identify reasons for nonuse among women with unmet need could also assist policymakers in developing a targeting strategy to increase the overall contraceptive prevalence rate. Serving these women may require a different approach, potentially including coordination between village midwives, fieldworkers, community volunteers, and other health-care workers.

These results may inform Indonesian policymakers and family planning program managers as they implement new solutions to promote clinical methods among appropriate populations and to increase the contraceptive prevalence rate. Although the Indonesian government's strategy to increase access to reproductive health service providers and additional contraceptive method types has allowed some women to switch method types, the results from Indonesia differ from the results of studies conducted in other settings where availability of additional method types has increased overall contraceptive prevalence (Jain 1989; Gray et al. 2006). In Indonesia, increasing access to additional services and counseling has not affected contraceptive prevalence. These results highlight the importance of context (for example, cultural and social factors), which affects reproductive health outcomes and should be considered by policymakers seeking to improve reproductive health. Increasing provision of contraceptive services and the method mix available has not resulted in increased prevalence. Demand-side issues associated with the acceptance and use of the varying contraceptive method types may be the key factors determining lack of additional contraceptive uptake and could be useful for appropriate and effective targeting.

\section{Acknowledgments}

The authors are grateful for comments provided by Siân Curtis. This study was partially supported by an award from the National Institute of Nursing Research.

\section{References}

Ahmed, Saifuddin; Li, Qingfeng; Liu, Li; Tsui, Amy O. Maternal deaths averted by contraceptive use: An analysis of 172 countries. Lancet. 2012; 380(9837):111-125. [PubMed: 22784531]

Angeles, Gustavo; Guilkey, David K.; Mroz, Thomas A. Purposive program placement and the estimation of family planning program effects in Tanzania. Journal of the American Statistical Association. 1998; 93(443):884-899.

Badan Kependudukan dan Keluarga Berencana Nasional (BKKBN). [Accessed 18 July 2012] Program Keluarga Berencana Target 4.595 Aksektor Baru. 2012a. http://www.bkkbn.go.id/beritadaerah/ Pages/Program-Keluarga-Berencana-Target-4.595-Aksektor-Baru.aspx

Badan Kependudukan dan Keluarga Berencana Nasional (BKKBN). [Accessed 18 July 2012] Ibu-ibu Antusias Ikut KB Gratis. 2012b. http://www.bkkbn.go.id/beritadaerah/Pages/Ibu-ibu-Antusias-IkutKB-Gratis.aspx 
Badan Kependudukan dan Keluarga Berencana Nasional (BKKBN). [Accessed 18 July 2012] Pelayanan KB Masuk Dalam Program Jaminan Sosial Nasional. 2012c. http://www.bkkbn.go.id/ ViewBerita.aspx?BeritaID=508

Canning, David; Schultz, Paul T. The economic consequences of reproductive health and family planning. Lancet. 2012; 380(9837):165-171. [PubMed: 22784535]

Carr, Bob; Gates, Melinda F.; Mitchell, Andrew; Shah, Rajiv. Giving women the power to plan their families. Lancet. 2012; 380(9837):80-82. [PubMed: 22784540]

Cleland, John; Bernstein, Stan; Ezeh, Alex; Faundes, Anibal; Glasier, Anna; Innes, Jolene. Family planning: The unfinished agenda. Lancet. 2006; 368(9549):1810-1827. [PubMed: 17113431]

Cleland, John; Conde-Agudelo, Agustin; Peterson, Herbert; Ross, John; Tsui, Amy. Contraception and health. Lancet. 2012; 380(9837):149-156. [PubMed: 22784533]

DeGraff, Deborah S.; Bilsborrow, Richard E.; Guilkey, David K. Community-level determinants of contraceptive use in the Philippines: A structural analysis. Demography. 1997; 34(3):385-398. [PubMed: 9275247]

Ekani-Bessala, Marie-Madeleine; Carre, Nicolas; Calvez, Thierry; Thonneau, Patrick. Prevalence and determinants of current contraceptive method use in a palm oil company in Cameroon. Contraception. 1998; 58(1):29-34. [PubMed: 9743893]

Fisher, Andrew A.; Prihartono, Joedo; Tuladhar, Jayanti; Hasan Hoesni, RM. An assessment of Norplant ${ }^{\circledR}$ removal in Indonesia. Studies in Family Planning. 1997; 28(4):308-316. [PubMed: 9431651]

Frankenberg, Elizabeth; Buttenheim, Alison; Sikoki, Bondan; Suriastini, Wayan. Do women increase their use of reproductive health care when it becomes more available? Evidence from Indonesia. Studies in Family Planning. 2009; 40(1):27-38. [PubMed: 19397183]

Frankenberg, Elizabeth; Karoly, Lynn. The 1993 Indonesian Family Life Survey: Overview and Field Report. Santa Monica, CA: RAND; 1995 a.

Frankenberg, Elizabeth; Karoly, Lynn. The 1993 Indonesia Family Life Survey: Appendix D, Users' Guide. Santa Monica, CA: RAND; 1995b.

Frankenberg, Elizabeth; Sikoki, Bondan; Suriastini, Wayan. Contraceptive use in a changing service environment: Evidence from Indonesia during the economic crisis. Studies in Family Planning. 2003; 34(2):103-116. [PubMed: 12889342]

Frankenberg, Elizabeth; Suriastini, Wayan; Thomas, Duncan. Can expanding access to basic healthcare improve children's health status? Lessons from Indonesia's Midwife in the Village Programme. Population Studies. 2005; 59(1):5-19. [PubMed: 15764131]

Frankenberg, Elizabeth; Thomas, Duncan. The Indonesia Family Life Survey: Study Design and Results from Waves 1 and 2. Santa Monica, CA: RAND; 2000.

Frankenberg, Elizabeth; Thomas, Duncan. Women's health and pregnancy outcomes: Do services make a difference? Demography. 2001; 38(2):253-265. [PubMed: 11392911]

Gertler, Paul J.; Molyneaux, John W. How economic development and family planning programs combined to reduce Indonesian fertility. Demography. 1994; 31(1):33-63. [PubMed: 8005342]

Glasier, Anna; Gülmezoglu, Metin; Schmid, George P.; Moreno, Claudia Garcia; Van Look, Paul FA. Sexual and reproductive health: A matter of life and death. Lancet. 2006; 368(9547):1595-1607. [PubMed: 17084760]

Gray, Andrew Lofts; Smit, Jennifer Ann; Manzini, Ntsiki; Beksinska, Mags. Report. Johannesburg: University of Witwatersrand; 2006. Systematic review of contraceptive medicines. Does choice make a difference?. http://archives.who.int/eml/expcom/expcom15/applications/sections/ ContraChoiceReview.pdf [Accessed 10 October 2011]

Hoke, Theresa H.; Wheeler, Stephanie B.; Lynd, Kelsey, et al. Community-based provision of injectable contraceptives in Madagascar: 'Task shifting' to expand access to injectable contraceptives. Health Policy and Planning. 201110.1093/heapol/czr003

Hull, Terence $\mathrm{H}$. The challenge of contraceptive implant removals in East Nusa Tenggara, Indonesia. International Family Planning Perspectives. 1998; 24(4):176-179. 205.

Hull, Terence H.; Hartanto, Wendy. Resolving contradictions in Indonesian fertility estimates. Bulletin of Indonesian Economic Studies. 2009; 1(45):61-71. 
Hull, Terence H.; Mosley, Henry. Revitalization of family planning in Indonesia. Bappenas, Indonesia: BKKBN and UNFPA; 2009.

Hull, Terence H.; Rusman, Roosmalawati; Hayes, Adrian C. Report for AusAID. Canberra, Australia: Research School for Social Sciences, Australian National University; 1998. Village midwives and the improvement of maternal and infant health in NTT and NTB.

Jain, Anrudh K. Fertility reduction and the quality of family planning services. Studies in Family Planning. 1989; 20(1):1-16. [PubMed: 2652381]

Jensen, Eric R. The fertility impact of alternative family planning distribution channels in Indonesia. Demography. 1996; 33(2):153-165. [PubMed: 8827162]

Kambo, Indra P.; Gupta, RN.; Kundu, AS.; Dhillon, BS.; Saxena, HM.; Saxena, Badri N. Use of traditional medical practitioners to deliver family planning services in Uttar Pradesh. Studies in Family Planning. 1994; 25(1):32-40. [PubMed: 8209393]

Khan, Shane; Mishra, Vinod; Arnold, Fred; Abderrahim, Noureddine. DHS Comparative Reports No. 16. Calverton, MD: Macro International; 2007. Contraceptive Trends in Developing Countries.

Koenig, Michael A.; Hossain, Mian Bazle; Whittaker, Maxine. The influence of quality of care upon contraceptive use in rural Bangladesh. Studies in Family Planning. 1997; 28(4):278-289. [PubMed: 9431649]

Konje, Justin C.; Oladini, F.; Otolorin, Emmanuel O.; Ladipo, Oladapo O. Factors determining the choice of contraceptive methods at the family planning clinic, University College Hospital, Ibadan, Nigeria. British Journal of Family Planning. 1998; 24(3):107-110. [PubMed: 9855717]

Krueger, Kristen; Akol, Angela; Wamala, Patricia; Brunie, Aurélie. Scaling up community provision of injectables through the public sector in Uganda. Studies in Family Planning. 2011; 42(2):117124. [PubMed: 21834413]

Lerman, Charles; Molyneaux, John W.; Moeljodihardjo, Soetedjo; Pandjaitan, Sahala. The correlation between family planning program inputs and contraceptive use in Indonesia. Studies in Family Planning. 1989; 20(1):26-37. [PubMed: 2711417]

Magadi, Monica A.; Curtis, Siân L. Trends and determinants of contraceptive method choice in Kenya. Studies in Family Planning. 2003; 34(3):149-159. [PubMed: 14558318]

Maralani, Vida. The changing relationship between family size and educational attainment over the course of socioeconomic development: Evidence from Indonesia. Demography. 2008; 45(3):693717. [PubMed: 18939668]

McKelvey, Christopher; Thomas, Duncan; Frankenberg, Elizabeth. Fertility regulation in an economic crisis. Economic Development and Cultural Change. 2012; 61(1):7-38.

Oddens BJ, Lehert P. Determinants of contraceptive use among women of reproductive age in Great Britain and Germany. I: Demographic factors. Journal of Biosocial Science. 1997; 29(4):415-435. [PubMed: 9881145]

RamaRao, Saumya; Lacuesta, Marlina; Costello, Marilou; Pangolibay, Blesilda; Jones, Heidi. The link between quality of care and contraceptive use. International Family Planning Perspectives. 2003; 29(2):76-84. [PubMed: 12783771]

Rosenzweig, Mark R.; Wolpin, Kenneth I. Evaluating the effects of optimally distributed public programs: Child health and family planning interventions. American Economic Review. 1986; 76(3):470-482.

Ross, John. Report. Jakarta, Indonesia: STARH Program, USAID; 2003. Contraceptive security in Indonesia: What do the data say?. http://pdf.usaid.gov/pdf_docs/PNACW746.pdf [Accessed 10 October 2011]

Schoemaker, Juan. Contraceptive use among the poor in Indonesia. International Family Planning Perspectives. 2005; 31(3):106-114. [PubMed: 16263527]

Schultz, T Paul. The gender and intergenerational consequences of the demographic dividend: An assessment of the micro- and macro linkages between the demographic transition and economic development. World Bank Economic Review. 2009; 23(3):427-442.

Schultz, T Paul; Zeng, Yi. Fertility of rural China: Effects of local family planning and health programs. Journal of Population Economics. 1995; 8(4):329-350. [PubMed: 12320113] 
Seiber, Eric E.; Bertrand, Jane T.; Sullivan, Tara M. Changes in contraceptive method mix in developing countries. International Family Planning Perspectives. 2007; 33(3):117-123. [PubMed: 17938094]

Statistics Indonesia (Badan Pusat Statistik [BPS]) and Macro International. Indonesia Demographic and Health Survey 2007. Calverton, MD: BPS and Macro International; 2008.

Statistics Indonesia (Badan Pusat Statistik [BPS]), National Population and Family Planning Board, Ministry of Health, and ICF International. Indonesia Demographic and Health Survey 2012: Preliminary Report. 2012. http://www.measuredhs.com/pubs/pdf/PR25/PR25.pdf

Steele, Fiona; Curtis, Siân. Appropriate methods for analyzing the effect of method choice on contraceptive discontinuation. Demography. 2003; 40(1):1-22. [PubMed: 12647511]

Steele, Fiona; Curtis, Siân L.; Choe, Minja. The impact of family planning service provision on contraceptive-use dynamics in Morocco. Studies in Family Planning. 1999; 30(1):28-42. [PubMed: 10216894]

Stephenson, Rob; Beke, Andy; Tshibangu, Delphin. Community and health facility influences on contraceptive method choice in the Eastern Cape, South Africa. International Family Planning Perspectives. 2008; 34(2):62-70. [PubMed: 18644757]

Strauss, John; Beegle, Kathleen; Sikoki, Bondan; Dwiyanto, Agus; Herawati, Yulia; Witoelar, Firman. The Third Wave of the Indonesia Family Life Survey: Overview and Field Report. Santa Monica, CA: RAND; 2004.

Strauss, John; Witoelar, Firman; Sikoki, Bondan; Wattie, Anna Marie. The Fourth Wave of the Indonesian Family Life Survey: Overview and Field Report. Santa Monica, CA: RAND; 2009.

Sultan, Mehboob; Cleland, John G.; Ali, Mohamed M. Assessment of a new approach to family planning services in rural Pakistan. American Journal of Public Health. 2002; 92(7):1168-1172. [PubMed: 12084703]

Syarief, Sugiri. Current and future policy and strategy of family planning program in Indonesia. Speech presented by BKKBN official at High Level Family Planning Consultation Meeting; Bangkok, Thailand. 8-10 December; 2010.

United Nations Population Fund (UNFPA). [Accessed 15 October 2010] Improving reproductive health. n.d. http://www.unfpa.org/rh/index.htm

Utomo, Iwu Dwisetyani; Arsyad, Syahmida S.; Hasmi, Eddy Nurul. Village family planning volunteers in Indonesia: Their role in the family planning programme. Reproductive Health Matters. 2006; 14(27):73-82. [PubMed: 16713881]

Warwick, Donald P. The Indonesian family planning program: Government influence and client choice. Population and Development Review. 1986; 12(3):453-490.

Wickstrom, Jane; Jacobstein, Roy. Contraceptive security: Incomplete without long-acting and permanent methods of family planning. Studies in Family Planning. 2011; 42(4):291-298. [PubMed: 22292248]

Withers, Melissa; Tavrow, Paula; Abe, Denise. Who meets their intentions to stop childbearing? Results of a longitudinal study in rural eastern Bali, Indonesia. Health Care for Women International. 2012; 33(9):814-832. [PubMed: 22891741]

World Bank. Report No. 9178-IND. 1991. Indonesia fifth population project (family planning and safe motherhood).

World Bank. Report No. 53327. 2010. Indonesia maternal health assessment.

World Health Organization (WHO). [Accessed 16 October 2010] Community-Based Distribution of Contraceptives: A Guide for Programme Managers. 1995. http://www.who.int/reproductivehealth/ publications/family_planning/9241544759/en/index.html

World Health Organization (WHO). [Accessed 28 March 2012] Maternal mortality. Fact sheet. 2010. http://www.who.int/mediacentre/factsheets/fs348/en/index.html 


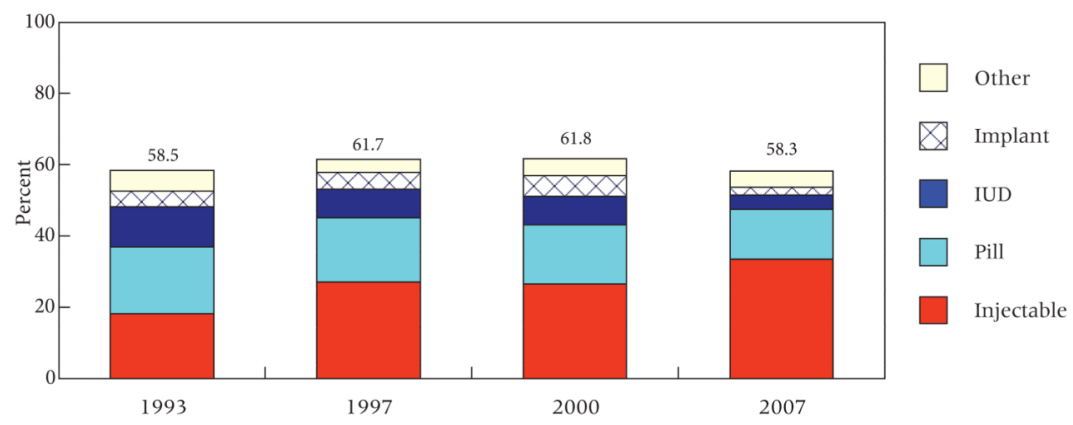

FIGURE 1.

Weighted estimates of percentage of women using a modern contraceptive method and type of method used, Indonesia, 1993-2007

SOURCE: Indonesia Family Life Survey, 1993, 1997, 2000, 2007. 


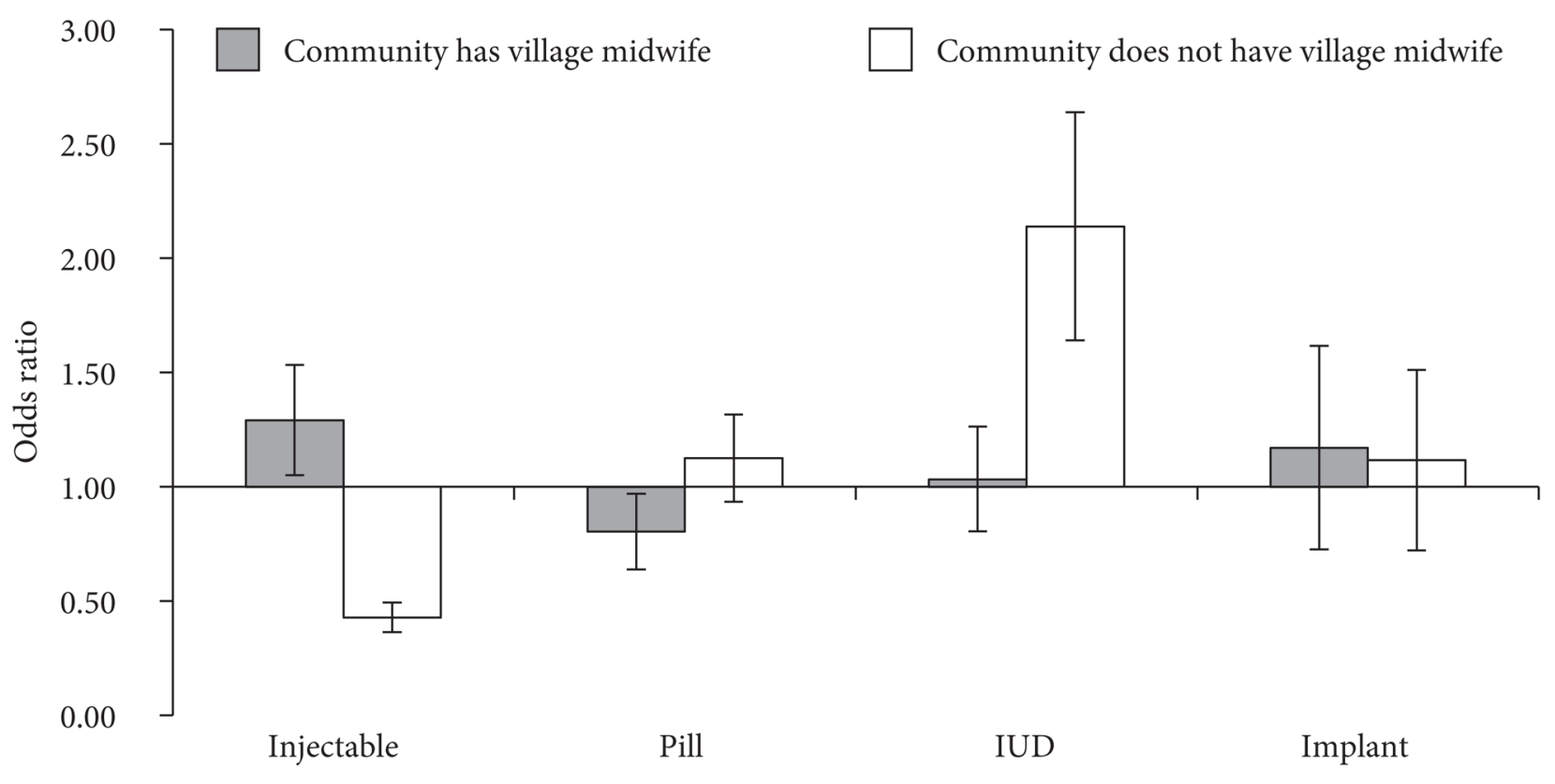

FIGURE 2.

Adjusted odds ratios of modern contraceptive method choice among women 30 years and older in communities with and without a village midwife, compared with women younger than 30 years of age in communities without a midwife, Indonesia, 1993-2007

NOTE: Error bars represent $95 \%$ confidence interval for each estimate. 


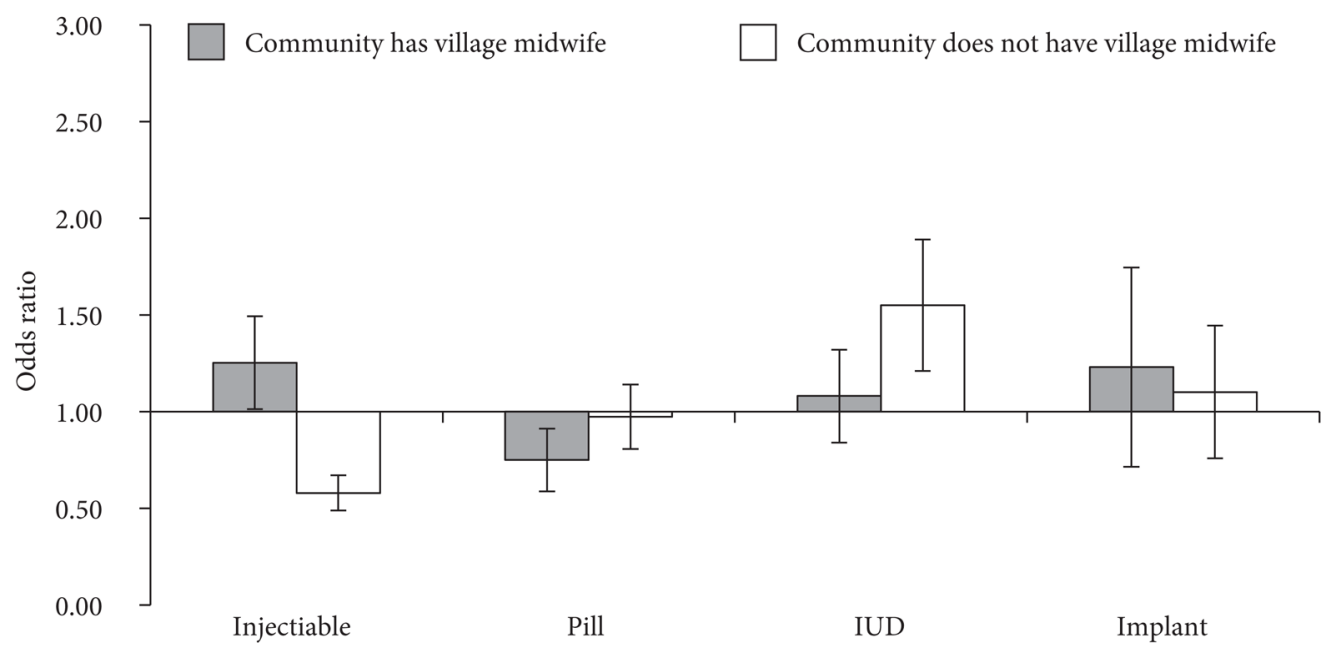

FIGURE 3.

Adjusted odds ratios of modern contraceptive method choice among women who have achieved their ideal family size in communities with and without a village midwife, compared with women who want more children in communities without a village midwife, Indonesia, 1993-2007

NOTE: Error bars represent 95\% confidence interval for each estimate. 


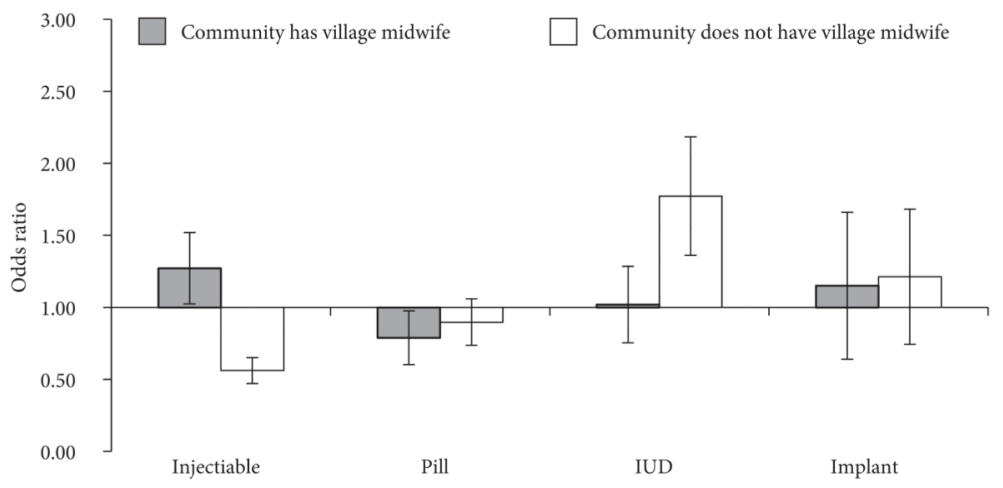

FIGURE 4.

Adjusted odds ratios of modern contraceptive method choice among women with 3 or more children in communities with and without a village midwife, compared with women having 0-2 children in communities without a village midwife, Indonesia, 1993-2007

NOTE: Error bars represent 95\% confidence interval for each estimate. 


\section{TABLE 1}

Odds ratios from logistic regression with fixed effects showing likelihood of modern contraceptive use, by village midwife availability and other selected community and individual characteristics, Indonesia, 19932007

\begin{tabular}{|c|c|}
\hline Characteristic & Odds ratio \\
\hline \multicolumn{2}{|l|}{ Community } \\
\hline Has village midwife & 1.03 \\
\hline \multicolumn{2}{|l|}{ Survey year } \\
\hline $1993(r)$ & - \\
\hline 1997 & $1.20^{\star}$ \\
\hline 1997-midwife interaction & 0.97 \\
\hline 2000 & $1.18 \star$ \\
\hline 2000-midwife interaction & 0.89 \\
\hline 2007 & 1.03 \\
\hline 2007-midwife interaction & 1.15 \\
\hline Hospitals (number) & 1.01 \\
\hline Public health clinics (number) & 1.00 \\
\hline Community health posts (number) & 1.00 \\
\hline Private providers (number) & 1.00 \\
\hline Main road is paved (percent) & 1.13 \\
\hline Community has public phone (percent) & 1.00 \\
\hline Households predominantly have private toilet facility (percent) & 0.93 \\
\hline Community has public sewer (percent) & 1.00 \\
\hline \multicolumn{2}{|l|}{ Woman } \\
\hline \multicolumn{2}{|l|}{ Age (years) } \\
\hline $15-19(\mathrm{r})$ & - \\
\hline $20-24$ & $1.91 \star \star \star$ \\
\hline $25-29$ & $2.27 \star \star \star$ \\
\hline $30-34$ & $2.16^{\star \star \star}$ \\
\hline $35-39$ & $1.94 \star \star \star$ \\
\hline $40-44$ & $1.52 \star \star \star$ \\
\hline $45-49$ & 1.08 \\
\hline \multicolumn{2}{|l|}{ Education (years) } \\
\hline $0(\mathrm{r})$ & - \\
\hline $1-5$ & 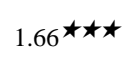 \\
\hline $6-9$ & $2.09 \star \star \star$ \\
\hline $10-12$ & $1.70 \star \star \star$ \\
\hline $13-19$ & $1.42 \star \star$ \\
\hline Household in top $50 \%$ real per capita expenditures & 1.03 \\
\hline Observations & 16,181 \\
\hline Fixed effects & 312 \\
\hline
\end{tabular}




\begin{tabular}{lc}
\hline Characteristic & Odds ratio \\
\hline Pseudo R-squared & 0.0866 \\
\hline${ }_{\text {Significant at } \mathrm{p} \leq 0.05 ;}$ \\
$\star \star \mathrm{p} \leq 0.01 ;$ \\
$\star \star \star \mathrm{p} \leq 0.001$. \\
$(\mathrm{r})=$ Reference category. $-=$ Not applicable.
\end{tabular}

NOTE: Odds ratios represent the change in odds of modern contraceptive use based on a one-unit change in the predictor variable. SOURCE: Indonesia Family Life Survey, 1993, 1997, 2000, 2007. 
$\bar{s}$

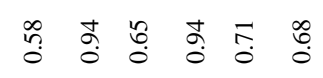

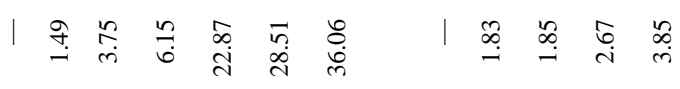

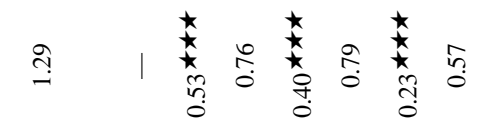

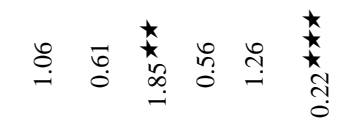

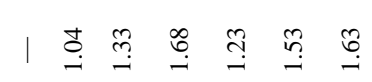

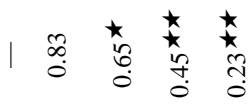

$\exists \quad 1$ gे

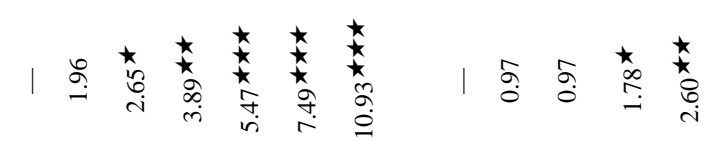

(n)

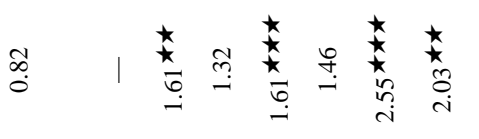

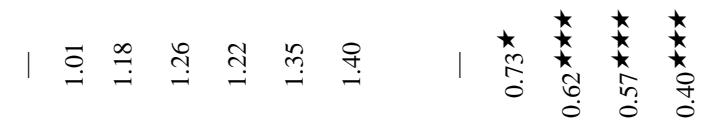

(2)

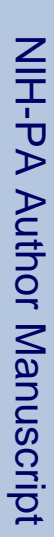

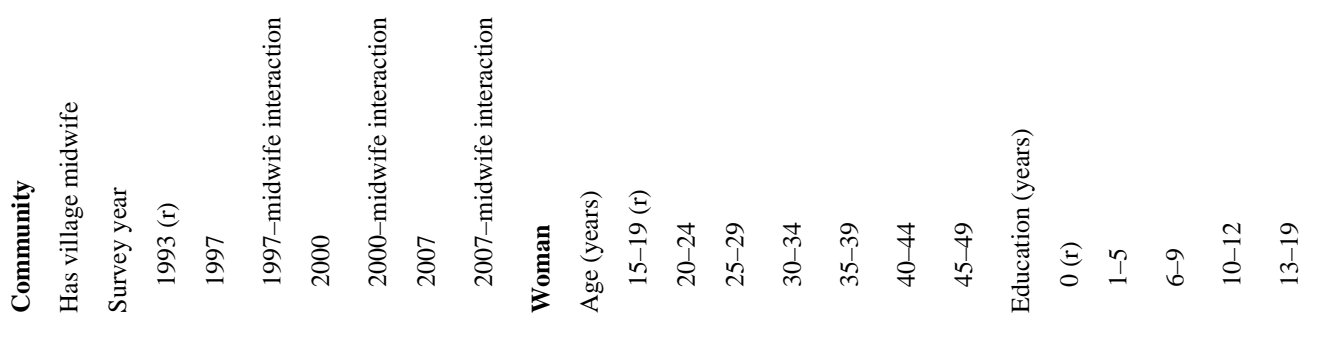




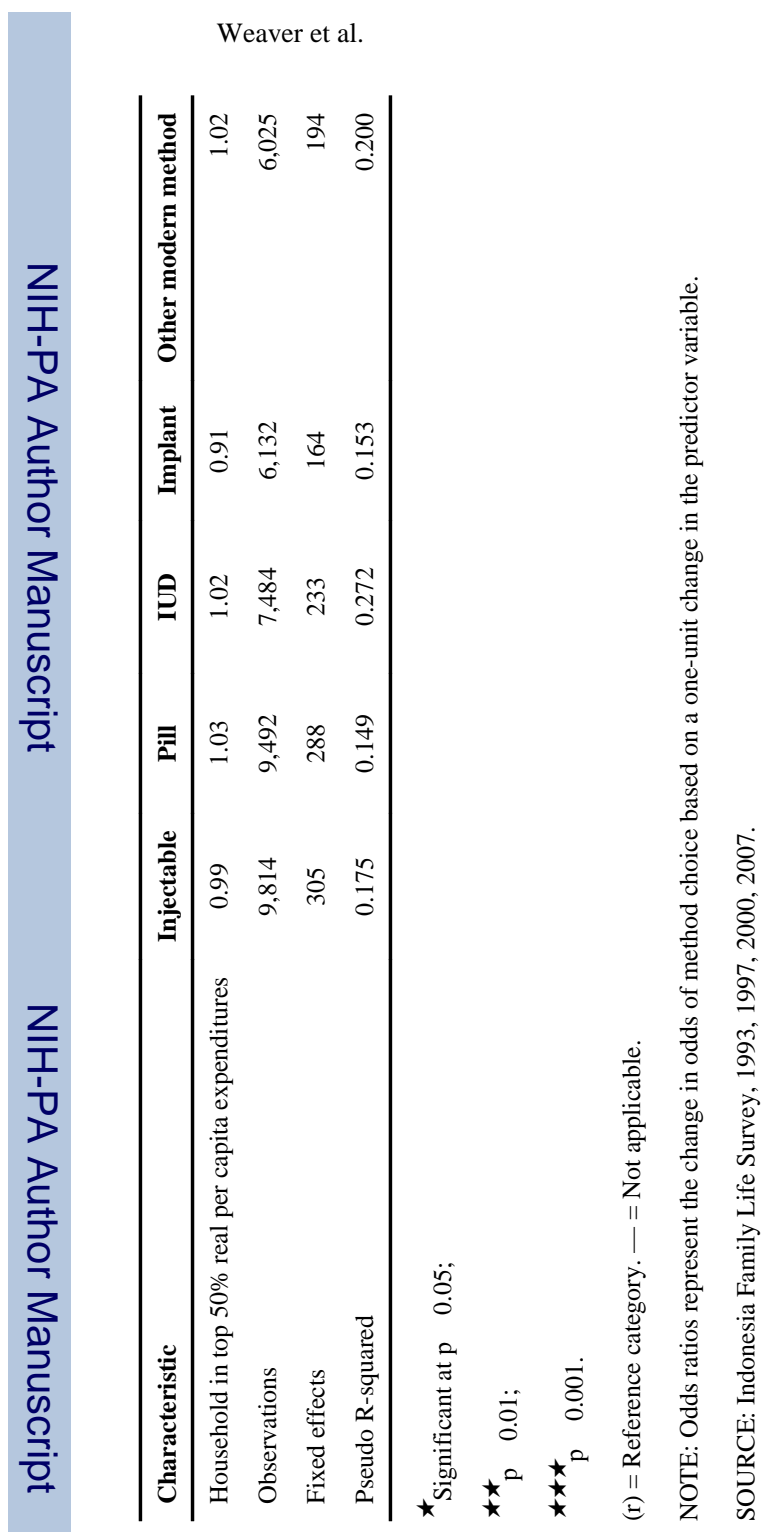

Stud Fam Plann. Author manuscript; available in PMC 2014 February 24. 


\section{TABLE 3}

Odds ratios of using a particular contraceptive method in Village Midwife Program communities, compared with use in 1993 in communities not having a village midwife, by year-midwife interaction, according to method, Indonesia, 1993-2007

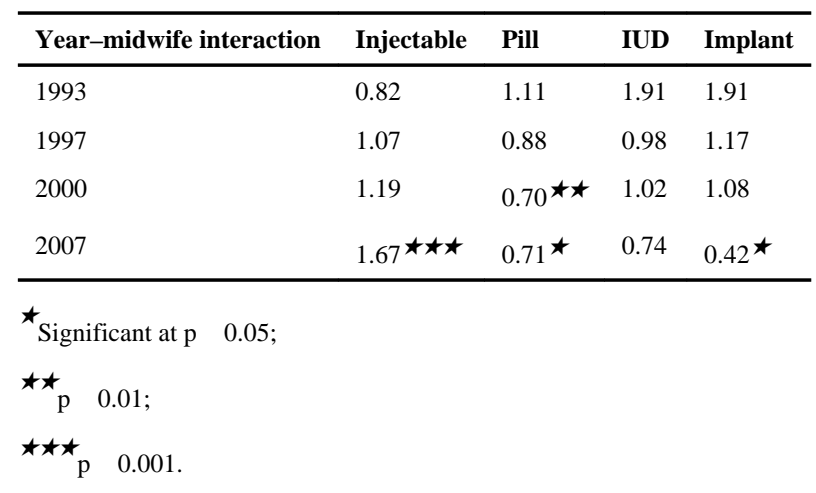

